\title{
The Renewal of Xinmin Food Market under the Background of "Relieving Beijing of Functions Nonessential to Its Role as the Capital"
}

\author{
Junzhe Wang ${ }^{1}$, and Yichi Zhang, ${ }^{2 *}$ \\ ${ }^{1}$ Beijing City University, Urban construction school, 100083 Beijing, China \\ ${ }^{2}$ University of Oslo, Department of Culture Studies and Oriental Languages, 0315 OSLO, Norway
}

\begin{abstract}
In response to the needs for "relieving Beijing of functions nonessential to its role as the capital", Beijing has fulfilled a series of tasks including old urban area renewal and population dispersion in the central urban area so as to strictly control the increment and effectively relieve the pressure over the stock. Some community food markets have been shut down, or regulated, transformed and upgraded. As a typical case, the Xinmin Food Market was renewed and upgraded in 2016, which has produced some impacts on consumers, business owners and managers. By taking the Xinmin Food Market as a case, this paper makes an in-depth survey and interview with its stakeholders, explores the pre-transformation problems and post-transformation improvements, analyzes the potential needs of consumers, business owners and administrators, summarizes the development status and improvement potential of food markets and propose the strategies for further renewal, with a view to providing references and suggestions for the optimization and upgrading of food markets in the old urban area.
\end{abstract}

\section{Introduction}

In the Community Food Market Specification of Beijing Municipality, the term "Community Food Market" means "a business place that retails staple and non-staple foods, including fruits, vegetables, meat, poultry, eggs and their products, aquatic products, dairy products, bean products, dried foods, seasonings, grain, edible oil and their products, etc".

In 1988, the former Ministry of Agriculture proposed the concept of "Non-staple Food Project", aiming to relieve the low supply of non-staple foods in China. Xinmin Food Market, located on the Gulouwai Street, was listed among the first "Non-staple Food Projects" of Beijing Municipality [1, 2, 3]. It was formally registered and established in March 1999.

In May 2016, while ensuring the needs for people's livelihoods, Beijing proposed the upgrading requirements relating to relieving Beijing of functions nonessential to its role as the capital, including dispersion of regional logistics bases and professional markets, and carried out a new round of transformation on community food markets. Just then, the Xinmin Food Market was transformed from the original "open air type" to "sheltered type" and finally to "enclosed type", making it a model in the transformation and upgrading of new food markets. In the September of the same year, the market witnessed a huge improvement in facilities, management and other aspects: widened access, less booths, installation of central air-conditioners, monitors and other hardware facilities, more perfect safety management, withdrawal of unqualified goods from the market, incoming goods inspection and acceptance and other management systems, hanging of evacuation plans and business licenses, announcement of complaint lines in an eye-catching place, etc.

As an important link of people's livelihood project, food markets are updated in real time alongside with urban development and appear vibrant. With the improvement of hardware facilities and management level, the business patterns and functions of food markets have changed unconsciously $[4,5]$.

\section{Comparative analysis on the conditions before and after transformation}

The object of this study is Xinmin Food Market, which is located at the northwest corner of Gulou Bridge in the North Second Ring Road (Old Gulou Outer Street, Xicheng District). The west side of it is the old Gulou Street, which is opposite to the North Binhe Park, the east side is the Gulou Street, and the south side is the Andingmen Xibinhe Road, which is next to the North Moat.

The area of this food market is about 5,000 square meters, with a total of 88 stores. Most of the surrounding residential areas were built between 1990 and 2000 .

\footnotetext{
* Corresponding author: yichizhangzyc@gmail.com
} 


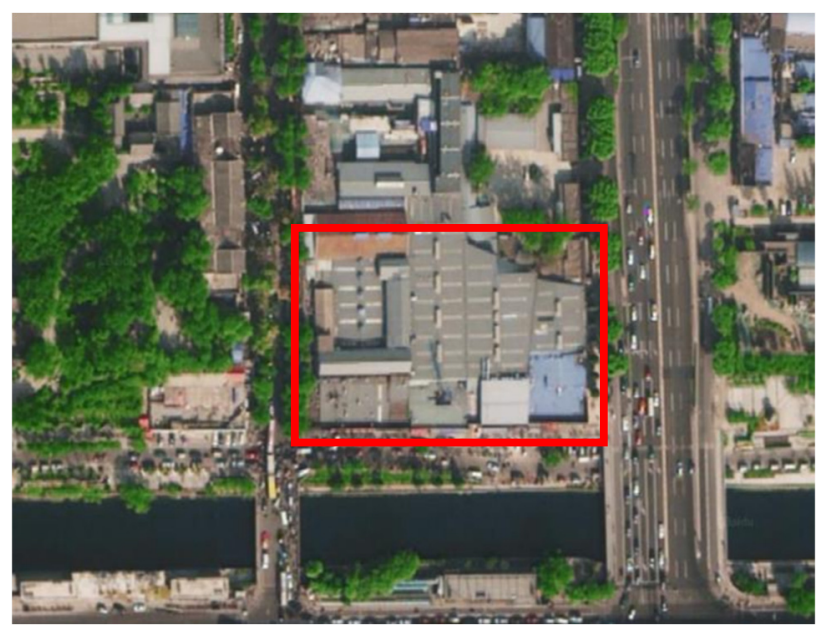

Fig. 1 The location of Xinmin Food Market

\subsection{Problems before transformation}

Before the transformation of the Xinmin Food Market, some areas were of sheltered type and featured insufficient fire facilities, bad shopping experience and poor safety, with a lack of management platforms and hardware facilities. Regarding the environmental problems, it was found through comparison between consumers and business owners that consumers (56\%) were sensitive towards crowed access and $22 \%$ of the business owners surveyed emphasized the dirty and disorderly market environment (Fig. 2).

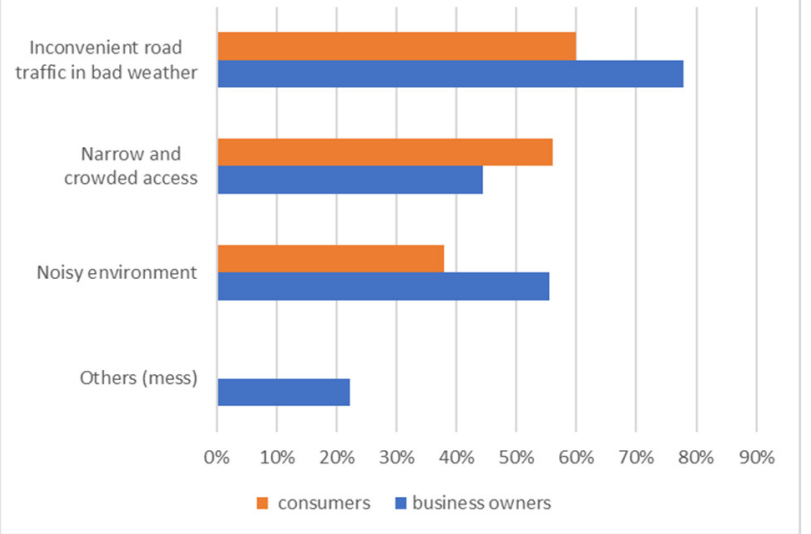

Fig. 2 Problems that existed before the transformation of the Xinmin Food Market

\subsection{Changes after transformation}

The renewed Xinmin Food Market has witnessed a significant improvement. The market enjoys a more comfortable temperature and has no extreme areas (neither too cold nor too hot). Although the widened channels cause the reduction in the quantity and size of booths, the spatial layout is more orderly. Consumers may have a more healthy and safe shopping environment. And great improvements have been made to the business orders and management level here.

Additionally, $40 \%$ of the consumers surveyed believed that the noisy shopping environment had been improved but only $11 \%$ of the business owners held the same idea (Fig. 3). It can be seen that consumers usually shop within a short duration. In addition to changed sanitation conditions, the reduction in noise has improved consumers' shopping experience. But business owners are insensitive to the change of noise as they are immersed in the noisy environment but pay more attention to the sanitation of the market environment.

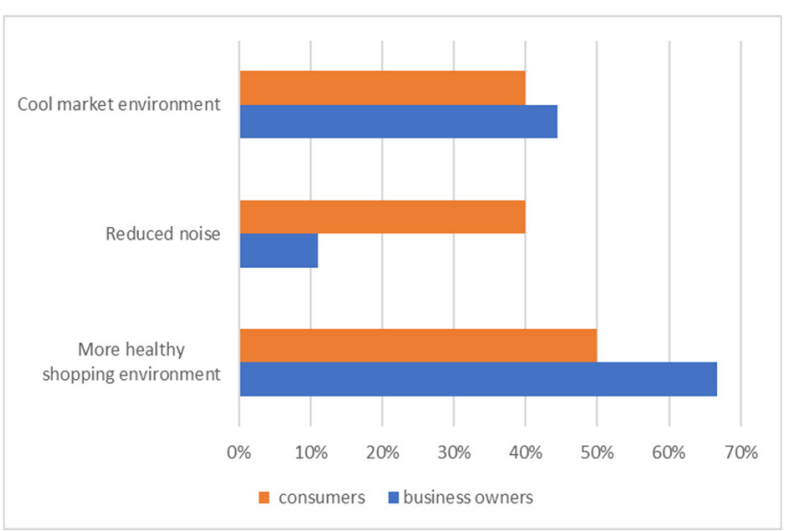

Fig. 3 Changes upon the renewal of Xinmin Food Market

\section{Potential needs analysis upon transformation}

Although the transformed Xinmin Food Market has improved consumers' shopping experience, some of their potential needs are still not satisfied or entirely ignored. Thus, it is important to analyze the potential needs during the short stay of consumers in food markets and the long stay of business owners in these markets, which is meaningful for the further improvement and transformation of food markets in the old urban area.

\subsection{Potential needs of consumers}

The residents living in the communities nearby share most of the consumers in the food market. Except shopping, about $25 \%$ populations went to the market purely for taking a walk or meeting and chatting with friends (Fig. 4). Based on the fact, consumers (74\%) hoped to add more space with seats in the market for their rests; also, $16 \%$ of the consumers surveyed hoped to have a simple dining area so that they could have their breakfasts, simple meals or semi-finished dinners there (Fig. 5).

- Shopping = Taking a walk = Meeting and chatting with friends

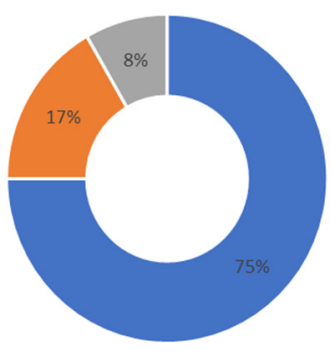

Fig. 4 Consumers' activities 


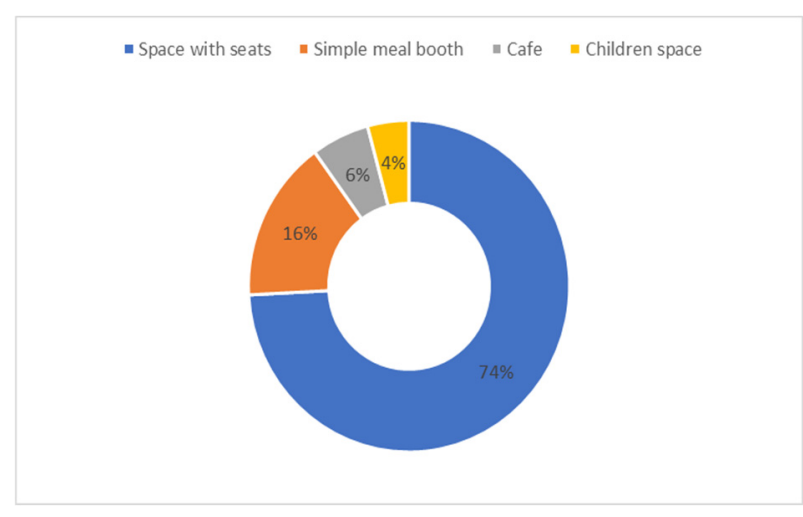

Fig. 5 Potential needs of consumers

\subsection{Potential needs of business owners}

Business owners have the urgent need of having their simple meals (work meals) as they stay in the food markets for long. $52 \%$ populations hoped to have more simple meal booths to solve their breakfast and lunch issues. The transformed market air-conditioner system remains insufficient in cooling and heating effect. $17 \%$ of the booth owners here proposed the need for system upgrading (Fig. 6). Also, 14\% of the business owners hoped to break the limitation of booth space and to add the auto sales or take-out channel to increase the consumer base and provide more convenience for consumers.

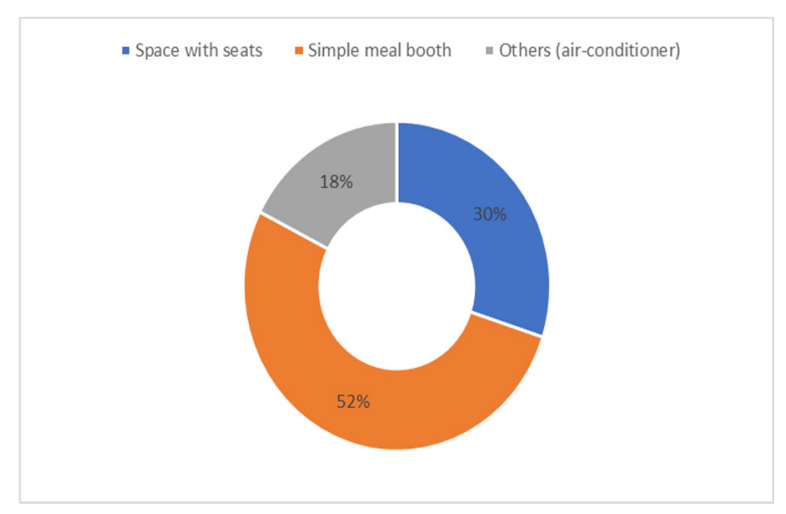

Fig. 6 Potential needs of business owners

\subsection{Potential needs of managers}

For food market managers, the most difficult issue is to ease the traffic jam caused by the concentration of personnel flow in the market. Currently, managers should spend plenty of time and efforts in clearly identifying parking places as well as numbering and coordinating transporting vehicles, guiding and coordinating these vehicles and those that go by so as to improve the road environment to some extent.

In view of the above, managers are considering sales online via the e-commerce platform so as to guide youths' shopping needs on the one hand and to improve space utilization rate and ease the traffic burden on the other hand.

\section{Suggestions}

\section{1 hardware scheme}

- Creating a new landmark by repositioning the regional market.

The Xinmin Food Market is located within the historical landscape conservation area of downtown Beijing. In accordance with related provisions as stipulated by The Outline of Beijing Municipal General Plan, we will take effective and efficient action to redesign associated infrastructure facilities, external and internal travel itineraries and functional structures and solve such pressing issues of parking and trucking. We will create an impressive landmark by preserving regional architectural styles.

- Improving its operating performance by utilizing limited space intensively and efficiently.

At present, the commercial space of the Xinmin Vegetable Market hasn't been efficiently utilized with its first floor kept overcrowded and second floor set aside. With its building height stringently regulated, we will take appropriate steps to further develop the commercial space of the second floor, thus expanding shopping space and meeting consumption demand.

- Optimizing its multiple functions by increasing open spaces and adjusting functional structures.

With the basic consumption demand satisfied, we will enhance spatial vitality and explore potential possibilities of its commercial space with the open spaces for both leisure and entertainment further increased; restructure its compact and restrained layout by improving lighting conditions and extending visual ranges; forge a convenient spatial structure by setting up road signs and marks of different colors and classifying shopping space into diverse areas; signal both exits and entrances and unify their style for consumers to identify them as soon as possible.

- Developing a safe and comfortable public space by renovating street landscapes and reshaping the characteristics of old Gulou Street.

Besides restructuring its internal commercial space, we will also continue to make a concerted effort to redesign and restructure its associated infrastructure facilities. With this, we will make it convenient and efficient for consumers and cargoes to enter and leave the market by regulating and controlling internal and external traffic flows. We will foster an atmosphere of and highlight cultural characteristics of old Beijing by redesigning the storefronts on old Gulou Street and regulating the parking lots concerned.

\section{2 operation scheme}

- Responding to the Internet Plus Initiative by pushing forward e-commerce.

The administrators shall take the initiative to analyze current consumption models and forge a smart vegetable market system while paying close attention to policy direction and upgrading hardware system. With this, we will reduce the commercial areas and transform them 
into more interesting functional areas, mitigate the sense of noise and chaos, increase the offline sales and extend the age range of consumer groups.

- Regulating local food brands by fostering a distinctive culinary culture.

Beijing boasts both distinctive culinary culture and household names like Bao ShiFu. But it is definitely difficult for us to identify such names at the vegetable markets. So the vegetable markets shall establish a close partnership with the food providers operating within and around Beijing to integrate the sources of vegetables and fruits, providing more choices and possibilities for local consumers.

- Fostering a new public exchange space by organizing both regular and festival events.

The regulatory agencies shall diversify exchange activities, increase the consumption demands of and enrich trading models of the exchange space by organizing festival events of seasonal fruits and vegetables and regular events of weekend fairs and gourmet festivals.

\section{Conclusions}

With the release of the new round of urban planning orientation and renewal requirements, Xinmin Food Market becomes more regulated and perfected and provides more convenience to the community residents nearby. Residents can establish smooth links with the market, build a trust mechanism within a small scope and are likely to spontaneously exchange. For the business owners that have stayed long, they have felt the significant improvement in the conditions of the food market and the huge changes upon transformation. The move does not guarantee the needs of people's livelihood but also becomes a pilot practice for the renewal of food markets in the old urban area. So, it is of great value and significance.

However, as a typical case of old urban area renewal, the renewal of Xinmin Food Market should not only be limited to environment sanitation, management and operation but also combine various potential needs and have their orientations adjusted. While satisfying the shopping needs, the market should have some personalized spaces, such as leisure and exchange areas, for functional adjustments. Additionally, the market should embrace new technologies more actively in its future development, introduce the e-commerce platform, enrich business management models, satisfy online and offline needs, follow the new trend of "Internet + " and march towards an intelligent market, expecting to become a new landmark for Beijing's project of people's livelihood.

\section{References}

1. C.Xing, The Role of Traditional Market in Urban Revitalization, Hefei University of Technology(2012)
2. S.J.Hu, Research on Public Markets in Contemporary Beijing Old City, Tsinghua University(2014)

3. J.Q.Wang, Some Consideration on the Public Participation in The Urban Renewal, City Planning Review,26(2002)

4. H.Wan, The Research on the Agricultural Trade Market Building Design of Urban Residential, Nanchang University(2010)

5. J.L.Wu, Research on the Planning of Public Wet Markets in Haidian District, Tsinghua University(2017) 